\title{
Analysis of the linear epitope for Fc-binding on the mouse IgG Fc receptor (moFcyRI) by synthetic peptide
}

\author{
F.Y. Wang ${ }^{1}$, J.Q. Guo ${ }^{1}$ and G.P. Zhang ${ }^{2}$ \\ ${ }^{1}$ Henan Key Laboratory for Animal Immunology, \\ Henan Academy of Agricultural Sciences, Zhengzhou, China \\ ${ }^{2}$ College of Animal Science and Veterinary Medicine, \\ Henan Agricultural University, Zhengzhou, China \\ Corresponding author: G.P. Zhang \\ E-mail: sprinkle.w@126.com
}

Genet. Mol. Res. 13 (2): 4647-4653 (2014)

Received June 17, 2013

Accepted November 18, 2013

Published June 18, 2014

DOI http://dx.doi.org/10.4238/2014.June.18.7

\begin{abstract}
To identify the linear epitope for Fc-binding to the mouse immunoglobulin $\mathrm{G}$ (IgG) Fc receptor (moFc $\gamma \mathrm{RI}$ ), peptides derived from the membrane-distal extracellular domain (EC2) of moFc $\gamma R I$, corresponding to the homologous region of human Fc $\gamma$ RI (huFc $\gamma \mathrm{RI}$ ) and huFc $\gamma \mathrm{RII}$, were synthesized. Using a dot-blot assay, six peptides were tested. The results showed that the moRI3 peptide (CVFYRNGKSFQFS) could combine with mouse IgG efficiently. A competitive enzyme-linked immunosorbent assay (ELISA) showed that the $\mathrm{IC}_{50}$ value of the moRI3 peptide was $38.03 \mu \mathrm{M}$. The moRI3 peptide could inhibit the combination of mouse IgG to the transfected COS 7 cells significantly with an $\mathrm{IC}_{50}$ value of $72.68 \mu \mathrm{M}$. The IgG-binding region of moFc $\gamma \mathrm{RI}$ was also localized in the $\mathrm{C}^{\prime}$-E loop of the EC2 domain as predicted according to huFc $\gamma \mathrm{RI}$ and huFc $\gamma \mathrm{RII}$. We predicted that the minimum effective IgG-binding region of moFc $\gamma$ RI may be the peptide ${ }^{153} \mathrm{SFQFSS}{ }^{158}$. The linear epitope for immunoglobulin-binding to mouse $\mathrm{F} c \gamma \mathrm{R}$ is also described. Thus, we generated a peptide that
\end{abstract}


targets a fundamental aspect of ligand recognition by this receptor class.

Key words: Fc-binding linear epitope; IgG; Fc $\gamma R I$; Synthetic peptide

\section{INTRODUCTION}

Fc $\gamma$ receptors (Fc $\gamma$ Rs), the receptors for the Fc portion of immunoglobulin $G(\operatorname{IgG})$, are essential for antibody-dependent immune responses (Ravetch and Kinet, 1991). There are two types of $\mathrm{Fc}$ receptors ( $\mathrm{FcRs}$ ), including activating receptors and inhibitory receptors, which transmit their signals via immunoreceptor tyrosine-based activation motifs and immunoreceptor tyrosine-based inhibitory motifs, respectively (Ravetch and Lanier, 2000). Mouse $\mathrm{Fc} \gamma \mathrm{RI}(\mathrm{moF} \gamma \mathrm{RI})$ is a key receptor involved in the development of immune responses (Gavin et al., 1998; Barnes et al., 2002; Ioan-Facsinay et al., 2002) and links innate and adaptive immunities via its dual roles as a low-affinity receptor for the T-independent IgG3 and as a highaffinity receptor for the T-dependent (Th1) IgG2a (Gavin et al., 1998; Barnes et al., 2002).

Linking the humoral and cellular responses, the mouse high-affinity receptor for $\mathrm{IgG}$, Fc $\gamma$ RI (CD64), is expressed on monocytes and macrophages and induced by interferon- $\gamma$ on neutrophils (Sivo et al., 1993). Although functions mediated by moFc $\gamma \mathrm{RI}$ are less well-characterized, cross-linking of human Fc $\gamma R I$ (huFc $\gamma R I$ ) on myeloid cells leads to events such as tyrosine phosphorylation, $\mathrm{Ca}^{2+}$ flux, superoxide generation, inflammatory mediator release, antibody-dependent cellular cytotoxicity, and internalization of small immune complexes (Scholl et al., 1992; Harrison et al., 1994) and have been intensively studied. Many of these sequelae may also be true in mice. Mouse Fc $\gamma R I$ is structurally homologous to huFc $\gamma R I$ and exhibits high-affinity binding of monomeric IgG (Scholl et al., 1992).

Protein engineering approaches suggest that interaction sites for cellular Fc $\gamma$ Rs are localized to the hinge proximal region of the $\mathrm{C}_{\mathrm{H}} 2$ domain (Sarmay et al., 1992; Shields et al., 2001). Crystal structures have been reported for extracellular portions of FcyRIIA (Maxwell et al., 1999), Fc $\gamma$ RIIB (Sondermann et al., 1999), Fc $\gamma$ RIIIB (Sondermann et al., 2000), FceRI (Takai et al., 1994), and Fc $\alpha$ RI (Morton et al., 1999). Peptides derived from human IgG have exhibited the capacity to interact with FcRs (Medgyesi et al., 2004; Uray et al., 2004). With respect to FcRs, ligand-binding regions in the receptors have been proposed based on structural and molecular analyses (Woof and Burton, 2004).

FcRs are important in the immune response; therefore, resolving the molecular interaction involved in their ligand binding may open up possibilities for modulating FcR-mediated mechanisms. In this study, we analyzed novel peptides designed by aligning the EC2 domain protein sequences of moFc $\gamma R I$, huFc $\gamma$ RI, and huFc $\gamma$ RIIA, and identified a consensus peptide sequence that binds Fc $\gamma \mathrm{RI}$ at a related site to IgG. Such an approach may be relevant for potential therapeutic interventions in inflammatory and autoimmune processes.

\section{MATERIAL AND METHODS}

\section{Peptide design and synthesis}

Based on the crystal structure of human Fc $\gamma$ RIIa, we analyzed the EC2 domain protein sequences of moFc $\gamma$ RI, huFc $\gamma$ RI, and huFc $\gamma$ RIIA (NCBI Protein Accession Nos. EDL38886, 
NP_000557 and NP_067674) with DNASIS 3.0 (MiraiBio, South San Francisco, CA, USA). Six peptides were designed corresponding to the sequence 117-192 of moFcrRI (Figure 1). The peptides were synthesized using a Symphony Multiplex Peptide Synthesizer (Protein Technologies, Inc., Tuscon, AZ, USA). Peptide purities were greater than $90 \%$ as assessed by high-performance liquid chromatography (HPLC) and mass spectrometry.

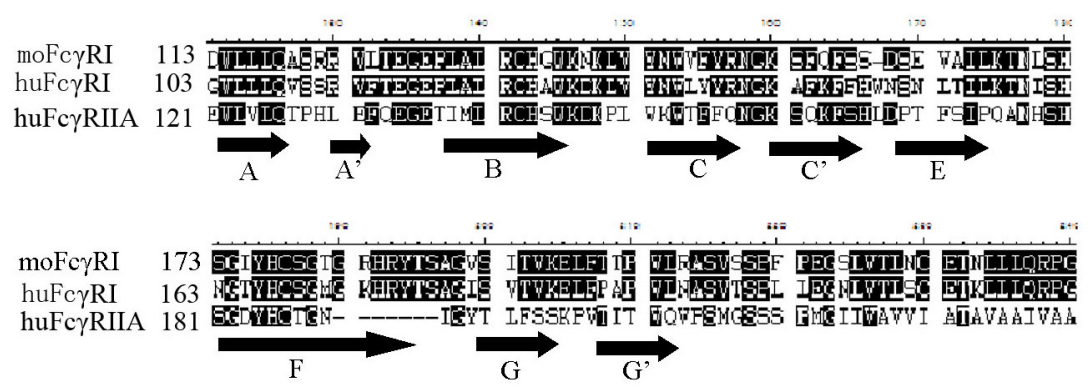

Figure 1. Alignment of the protein sequences of moFc $\gamma$ RI, huFc $\gamma$ RI and huFc $\gamma$ RIIA (NCBI protein accession Nos. EDL38886, NP_000557 and NP_067674). The black highlights indicate that two or three sequences are identical, and dotted lines represent deletions of amino acids.

\section{Dot-blot assay}

According to the method of Zhang et al. (2006), a dot-blot assay was developed to test the binding of mouse IgG to different moFc $\gamma \mathrm{RI}$ peptides. The bovine serum albumin (BSA)coupled peptides were blotted onto nitrocellulose membranes (Millipore, Billerica, MA, USA) at different concentrations and the soluble moFc $\gamma$ RI protein $(\mathrm{smoFcp})$ and carrier protein BSA were used as positive and negative controls, respectively. After air drying, the membrane was blocked with $0.2 \%$ gelatin in $0.01 \mathrm{M}$ phosphate-buffered saline (PBS), $\mathrm{pH} 7.2$, containing $0.05 \%$ Tween 20 (PBST) at $37^{\circ} \mathrm{C}$ for $1 \mathrm{~h}$, and then incubated with $10 \mu \mathrm{g} / \mathrm{mL}$ horseradish peroxidase (HRP)conjugated mouse IgG (HRP-IgG) in PBST containing $0.2 \%$ gelatin at $37^{\circ} \mathrm{C}$ for $1 \mathrm{~h}$ followed by thorough washing with PBST. Color was developed by using a 3-amino-9-ethylcarbazole staining kit (Zhongshan Goldenbridge, Beijing, China) according to manufacturer instructions.

\section{Competitive enzyme-linked immunosorbent assay (ELISA)}

The inhibitory capacity of the moRI3 peptide was measured using the competitive ELISA (Zhang et al., 2006). High-binding ELISA plates were coated with the recombinant moFc $\gamma R$ I protein at $10 \mu \mathrm{g} / \mathrm{mL}$ at $4^{\circ} \mathrm{C}$ overnight. Next, the plates were blocked with $0.2 \%$ gelatin at room temperature for $2 \mathrm{~h}$. In the competition assay, $50 \mathrm{nM}$ HRP-IgG was pre-incubated with various concentrations $(5-640 \mu \mathrm{M})$ of moRI3 peptide at $4^{\circ} \mathrm{C}$ for $2 \mathrm{~h}$. The mixed samples were then transferred to the plates for IgG binding with an incubation of $1 \mathrm{~h}$ at $37^{\circ} \mathrm{C} .3,30,5,50$-Tetramethylbenzidine (Sigma, St. Louis, MO, USA) was used as the chromogen for the color development. The reaction was stopped by the addition of $1 \mathrm{M}$ sulfuric acid, and the absorbance values of the samples were measured at $450 \mathrm{~nm}$. The moRI2 peptide and BSA were used as negative controls, and all experiments were carried out in triplicate. Binding of mouse IgG to the coated recombinant moFc $\gamma \mathrm{RI}$ protein without the inhibiting peptide $\left(\mathrm{B}_{0}\right)$ was considered to be $100 \%$ binding. For each peptide 
concentration, the inhibition percentage $(\mathrm{Ic} \%)$ was calculated as $\mathrm{Ic} \%=(\mathrm{Bn}-\mathrm{Bi}) / \mathrm{B} 0 \times 100 \%$, where $B i$ and $B n$ are the IgG binding of the inhibiting and negative peptides, respectively, at corresponding peptide concentrations. The amount of added peptide required to inhibit IgG binding by $50 \%\left(\mathrm{IC}_{50}\right)$ was calculated based on peptide concentration.

\section{Flow cytometry analysis}

Cells were harvested using $1 \mathrm{mM}$ EDTA, washed, and resuspended in cold serum-free Dulbecco's modified Eagle's medium (DMEM) (Gibco, Grand Island, NY, USA) containing $0.1 \%$ sodium azide. Fifty microliter diluted aggregates were added to cells, mixed, and incubated at $4{ }^{\circ} \mathrm{C}$ for $2 \mathrm{~h}$. Cells were washed twice with cold PBS containing $0.1 \%$ sodium azide and transferred to $500 \mu \mathrm{L}$ cold sheath fluid per sample. For the inhibition experiments, fluorescein isothiocyanate (FITC)-labeled IgG aggregates were pre-incubated, respectively, with various concentrations of moRI3 peptide $(5-640 \mu \mathrm{M})$ or control at $4^{\circ} \mathrm{C}$ for $2 \mathrm{~h}$. All experiments were carried out in triplicate. Fluorescent intensity of the samples (counting 10,000 cells per sample) was measured on a FACSCalibur system (Becton Dickinson, Franklin Lakes, NJ, USA).

\section{RESULTS AND DISCUSSION}

Depending on the alignment of the EC2 domain protein sequences of moFc $\gamma \mathrm{RI}$, huFc$\gamma \mathrm{RI}$, and huFc $\gamma$ RIIA, six peptides (moRI1-moRI6) were designed covering the loops of A-B, B-C, C-C', C'-F, F, and F-G, respectively (Table 1). Binding of mouse IgG to the six peptides was tested using a dot-blot assay. The results showed that HRP-IgG only bound to the third peptide, moRI3 $\left({ }^{146}(\mathrm{C})\right.$ VFYRNGKSFQFS $\left.{ }^{156}\right)$. Different moRI3 concentrations were tested for binding to mouse $\operatorname{IgG}$ (Figure 2).

Table 1. Details of six peptides covering the loops of A-B, B-C, C-C', C'-F, F, and F-G.

\begin{tabular}{|c|c|c|c|c|c|c|}
\hline Code & Sequence $^{1}$ & Length (aa) & Mass (Da) & $\mathrm{p} I$ & IgG binding ${ }^{2}$ & Predicted position \\
\hline$\overline{\mathrm{moRI}}$ & ${ }^{117}(\mathrm{C})$ QASRRVLTEGEPLALR ${ }^{133}$ & 17 & 1899.10 & 9.54 & - & A-B loop \\
\hline moRI2 & ${ }^{134} \mathrm{CHGWKNKLVYNV}^{145}$ & 12 & 1460.67 & 9.98 & - & B-C loop \\
\hline moRI3 & ${ }^{146}(\mathrm{C})$ VFYRNGKSFQFS ${ }^{156}$ & 13 & 1582.74 & 10.14 & + & $C^{\prime}-E$ loop \\
\hline moRI4 & ${ }^{157}(\mathrm{C})$ SSDSEVAILK $^{166}$ & 11 & 1151.28 & 4.11 & - & E region \\
\hline moRI5 & ${ }^{167}(\mathrm{C})$TNLSHSGIYH $^{176}$ & 11 & 1281.80 & 7.81 & - & E-F loop \\
\hline moRI6 & ${ }^{177}$ CSGTGRHRYTSAGVSI ${ }^{192}$ & 16 & 1651.74 & 10.44 & - & F-G loop \\
\hline
\end{tabular}

${ }^{1}$ The Cys residue added to the N-terminus of the peptides for conjugation is listed in parentheses. ${ }^{2}$ The binding of mouse IgG to the BSA-conjugated peptide was tested by the dot-blot assay. "+" represents specific binding of mouse IgG bound to the peptide, and "-" means that binding was not detected.

The inhibitory effect of moRI3 on mouse IgG binding to moFc $\gamma$ RI was evaluated by competitive ELISA. The moRI3 peptide inhibited the combination of mouse IgG to soluble moFc $\gamma R$ I coated on the plate (Figure 3 ). The $\mathrm{IC}_{50}$ value of the moRI3 peptide was $38.02 \mu \mathrm{M}$ after non-specific inhibition of the control peptide was subtracted.

Inhibition by the moRI3 peptide was determined by calculating the percentages of cells showing fluorescence. Figure 4 shows that the peptide moRI 3 inhibited the binding of mouse IgG on the transfected COS 7 cells. The $\mathrm{IC}_{50}$ value of the moRI3 peptide was 72.68 $\mu \mathrm{M}$. Because there was no inhibition effect at each concentration, the moRI2 peptide and BSA were used as negative controls. 


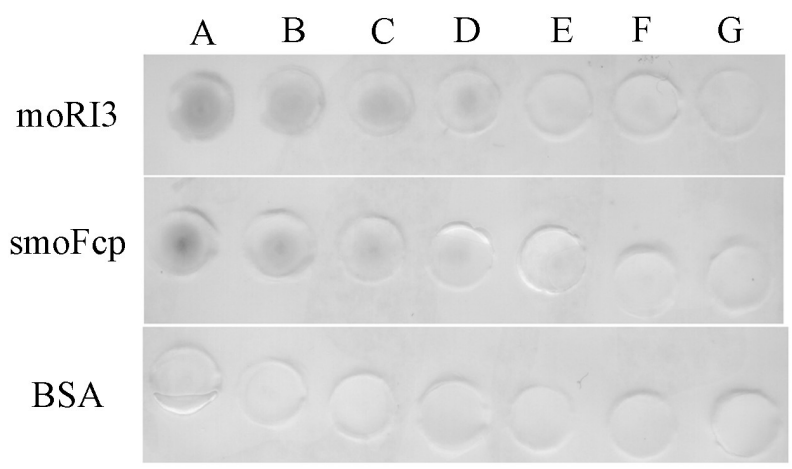

Figure 2. Binding of mouse IgG to the BSA, moRI2 and moRI3 peptides. The BSA-coupled peptides were blotted onto nitrocellulose membranes at different contents and the soluble moFc $\gamma \mathrm{RI}$ protein $(\mathrm{smoFcp})$ and carrier protein BSA were used as positive and negative controls, respectively. A-G represents the different contents $(20,10,5,2.5$, $1.25,0.625$, and $0 \mu \mathrm{g}$, respectively) of BSA, smoFcp and moR3 peptides.

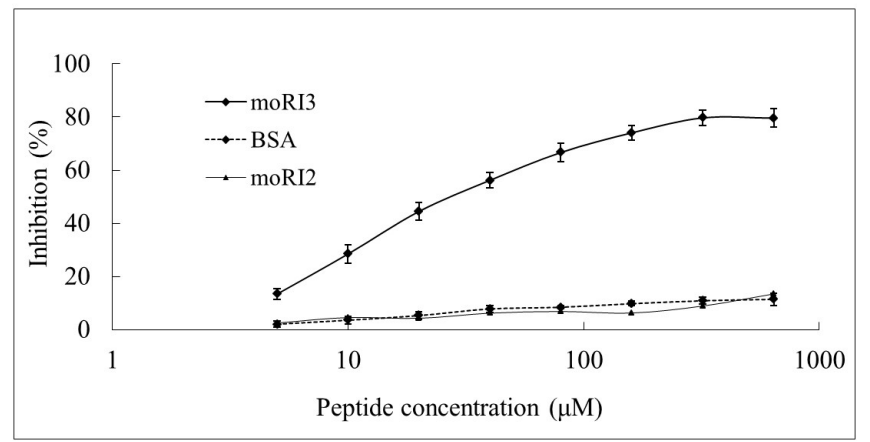

Figure 3. Inhibition of IgG binding to soluble moFc $\gamma$ RI. HRP-IgG was pre-incubated, respectively, with the peptide moRI3 at different concentrations $(5-640 \mu \mathrm{M})$ at $4^{\circ} \mathrm{C}$ for $2 \mathrm{~h}$ using control peptide (moRI2) and BSA as negative control.

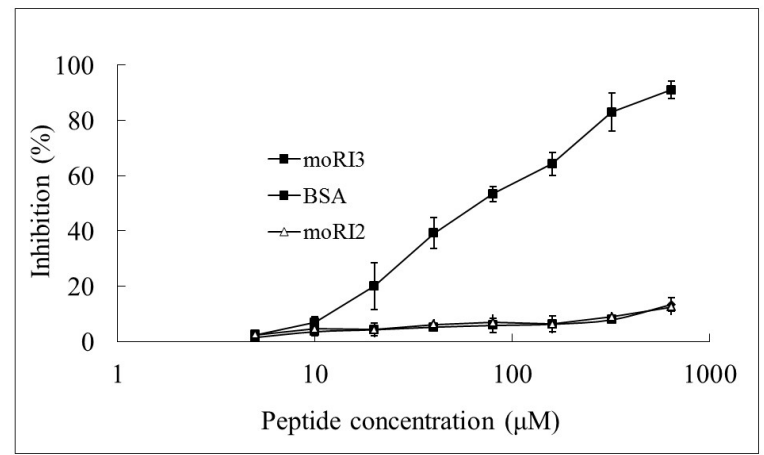

Figure 4. Inhibition of $\mathrm{IgG} /$ receptor interaction by the moRI3 peptide. FITC-labeled IgG aggregates were preincubated with various concentrations of the moRI3 peptide $(5-640 \mu \mathrm{M})$ or control at $4^{\circ} \mathrm{C}$ for $2 \mathrm{~h}$, and then applied to the transfected COS 7 cells. Fluorescent spectra were analyzed by flow cytometry (BD, FACSCalibur) counting 10,000 cells per sample. 
In this study, we developed a linear epitope for Ig-binding on mouse Fc $\gamma$ R. The moRI3 peptide $\left({ }^{146}(\mathrm{C})\right.$ VFYRNGKSFQFS $\left.{ }^{156}\right)$ possesses binding capability to mouse IgG. According to sequence alignment, we found that moRI3 is located in the C'-E loop of the EC2 domain. The extracellular regions of FcyRs share the same overall heart-shaped structure in which the two domains are positioned at an acute angle to each other and share a large interface. Each of the EC1 and EC2 domains of all the receptors are arranged into an identical overall Ig-fold composed of $\beta$-strands labeled as AA'BCC'EFG from the amino-terminus (Zhang et al., 2006). The overall fold of two IgG-like domains in a sharply bent structure is shared by Fc $\gamma$ RIII, Fc $\gamma R I I a / b$, and FceRI $\alpha$, as observed in the crystal structures (Sondermann et al., 2000). The binding region of the FcR to the Fc fragments has been identified in the Fc $\gamma \mathrm{RIII} /$ $\mathrm{hFc} 1$ and $\mathrm{Fc} \varepsilon \mathrm{RI} / \mathrm{IgE}-\mathrm{Fc}-$ fragment complex structures. It consists mainly of rather flexible loops that rearrange upon complex formation. The $\mathrm{B} / \mathrm{C}, \mathrm{C}^{\prime} / \mathrm{E}$, and $\mathrm{F} / \mathrm{G}$ loops, as well as the $\mathrm{C}^{\prime}$ strand, carry the contact residues in the $\mathrm{Fc} \gamma \mathrm{RIII} / \mathrm{hFc} 1$ structure and contain conserved amino acid residues that share common binding principles as well as sequence variations for the generation of specificity (Sondermann et al., 2000). The structure of Fc $\gamma$ RIIa was determined previously and shows the same overall fold as described for Fc $\gamma$ RIII. The reported structure originates from crystals of space group $P 2_{1}, 2$, , and the molecules form a dimer about one of the crystallographic dyads. This arrangement results in a dominant crystal contact, indicating that a dimer of FcyRIIa recognizes IgG. In this dimer, the molecules contact each other via the $\mathrm{CC}^{\prime} \mathrm{FG}$ sheets and the $\mathrm{C} / \mathrm{C}^{\prime}$ loop of the $\mathrm{C}$-terminal domain. Our results showed that the IgGbinding region of moFcyRI was also localized in the $\mathrm{C}^{\prime}$-E loop of the EC2 domain. This is in agreement with the structures of huFc $\gamma \mathrm{RI}$ and huFc $\gamma \mathrm{RII}$.

To effectively examine the IgG-binding region, the peptides were first designed to be longer. According to the minimum effective IgG-binding region of huFc $\gamma \mathrm{RI}$ and huFc $\gamma \mathrm{RIIA}$ $\left(C^{\prime}-E\right)$, we predicted that the effective IgG-binding region of moFc $\gamma \mathrm{RI}$ was likely the peptide ${ }^{153} \mathrm{SFQFSS}{ }^{158}$. This will be confirmed in future studies. Thus, we generated a peptide that targets a fundamental aspect of ligand recognition by this receptor class. We hypothesize that a peptide derived from the Fc-binding site of the receptor would be a better candidate for the downregulation of FcR-initiated inflammatory responses.

\section{ACKNOWLEDGMENTS}

Research supported by the China Postdoctoral Science Foundation (\#20090460856) and a grant from the key program of the National Natural Science Foundation of China (\#30730068).

\section{REFERENCES}

Barnes N, Gavin AL, Tan PS, Mottram P, et al. (2002). FcgammaRI-deficient mice show multiple alterations to inflammatory and immune responses. Immunity 16: 379-389.

Gavin AL, Barnes N, Dijstelbloem HM and Hogarth PM (1998). Identification of the mouse IgG3 receptor: implications for antibody effector function at the interface between innate and adaptive immunity. J. Immunol. 160: 20-23.

Harrison PT, Davis W, Norman JC, Hockaday AR, et al. (1994). Binding of monomeric immunoglobulin G triggers Fc gamma RI-mediated endocytosis. J. Biol. Chem. 269: 24396-24402.

Ioan-Facsinay A, de Kimpe SJ, Hellwig SM, van Lent PL, et al. (2002). FcgammaRI (CD64) contributes substantially to severity of arthritis, hypersensitivity responses, and protection from bacterial infection. Immunity 16: 391-402.

Maxwell KF, Powell MS, Hulett MD, Barton PA, et al. (1999). Crystal structure of the human leukocyte Fc receptor, Fc 
gammaRIIa. Nat. Struct. Biol 6: 437-442.

Medgyesi D, Uray K, Sallai K, Hudecz F, et al. (2004). Functional mapping of the Fe gamma RII binding site on human IgG1 by synthetic peptides. Eur. J. Immunol. 34: 1127-1135.

Morton HC, van Zandbergen G, van Kooten C, Howard CJ, et al. (1999). Immunoglobulin-binding sites of human FcalphaRI (CD89) and bovine Fcgamma2R are located in their membrane-distal extracellular domains. J. Exp. Med 189: $1715-1722$.

Ravetch JV and Kinet JP (1991). Fc receptors. Annu. Rev. Immunol. 9: 457-492.

Ravetch JV and Lanier LL (2000). Immune inhibitory receptors. Science 290: 84-89.

Sarmay G, Lund J, Rozsnyay Z, Gergely J, et al. (1992). Mapping and comparison of the interaction sites on the Fc region of IgG responsible for triggering antibody dependent cellular cytotoxicity (ADCC) through different types of human Fc gamma receptor. Mol. Immunol. 29: 633-639.

Scholl PR, Ahern D and Geha RS (1992). Protein tyrosine phosphorylation induced via the IgG receptors Fc gamma Ri and Fc gamma RII in the human monocytic cell line THP-1. J. Immunol. 149: 1751-1757.

Shields RL, Namenuk AK, Hong K, Meng YG, et al. (2001). High resolution mapping of the binding site on human IgG1 for Fe gamma RI, Fc gamma RII, Fc gamma RIII, and FcRn and design of IgG1 variants with improved binding to the Fc gamma R. J. Biol Chem. 276: 6591-6604.

Sivo J, Politis AD and Vogel SN (1993). Differential effects of interferon-gamma and glucocorticoids on Fc gamma R gene expression in murine macrophages. J. Leukoc. Biol 54: 451-457.

Sondermann P, Huber R and Jacob U (1999). Crystal structure of the soluble form of the human fcgamma-receptor IIb: a new member of the immunoglobulin superfamily at 1.7 A resolution. EMBO J. 18: 1095-1103.

Sondermann P, Huber R, Oosthuizen V and Jacob U (2000). The 3.2-A crystal structure of the human IgG1 Fc fragmentFc gammaRIII complex. Nature 406: 267-273.

Takai T, Li M, Sylvestre D, Clynes R, et al. (1994). FcR gamma chain deletion results in pleiotrophic effector cell defects. Cell 76: 519-529.

Uray K, Medgyesi D, Hilbert A, Sarmay G, et al. (2004). Synthesis and receptor binding of IgG1 peptides derived from the IgG Fc region. J. Mol. Recognit. 17: 95-105.

Woof JM and Burton DR (2004). Human antibody-Fc receptor interactions illuminated by crystal structures. Nat. Rev. Immunol. 4: 89-99.

Zhang G, Guo J, Zhou J, Wang X, et al. (2006). Identification of the linear epitope for Fc-binding on the bovine IgG2 Fc receptor (boFcgamma2R) using synthetic peptides. FEBS Lett. 580: 1383-1390. 